\title{
A prototype analysis of New Zealand adolescents' conceptualizations of wellbeing
}

\author{
Gazal Bharara · Scott Duncan · Aaron Jarden · Erica Hinckson
}

\begin{abstract}
This research investigated New Zealand adolescents' (aged 11 to 13, $N=361$ ) perceptions of wellbeing from a prototype perspective. Specifically, three studies examined what constitutes and promotes wellbeing, whether adolescents' perspectives are aligned with adults' conceptualizations and academic models of wellbeing, whether socioeconomic status influences adolescents' conceptualization, and whether wellbeing is prototypically organized. Results showed that wellbeing is prototypically organized as some components are more central to the concept of wellbeing and others more peripheral. Contrary to lay adults' conceptualizations and popular wellbeing models, adolescents consider enjoyment/having fun, feeling safe, and being kind/helpful as central components of wellbeing, and sense of satisfaction as a peripheral component of wellbeing. Furthermore, low socio-economic status adolescents consider comfort/being wealthy, being focused, good physical health, good values, and success/achievements as more central for wellbeing than highsocioeconomic status adolescents. Consistent with the current literature, positive family relationships, positive friendships, and physical activity/sport were the most frequently reported pathways to wellbeing among adolescents. Overall, researchers and practitioners should consider adolescents' understanding of wellbeing in the development of wellbeing assessments and interventions.
\end{abstract}

Keywords: adolescents, prototype analysis, wellbeing, well-being, perspectives, components

\section{Introduction}

Over the last decades adolescent wellbeing has received increasing attention at macro and micro levels (Andresen, Bradshaw, \& Kosher, 2019; Rees \& Dinisman, 2015). The United Nations (1989) has declared wellbeing is a basic right for adolescents and that their views must be obtained in all matters that affect them. Both national and international governments as well as adolescent wellbeing scientists have emphasized the importance of greater participation of adolescents in conceptualizing wellbeing and considering adolescents' conceptions in wellbeing models, programs, and policies (Ben-Arieh, 2005; Ben-Arieh, Casas, Frønes, \& Korbin, 2014; Bourke \& Geldens, 2007; Casas, 2011; Education Review Office, 2013, 2015b; Education Services Australia, n.d.; Fattore, Mason, \& Watson, 2007; Ministry of Youth Development, 2004).

A lack in consensus over the conceptualizations of wellbeing is a potential impediment to the progress, as well as the precision, of wellbeing science. Researchers conceptualize wellbeing in partly distinct ways (Hone, Jarden, Schofield, \& Duncan, 2014) and perceptions of adolescents are likely to differ to adults' (Fattore et al., 2007; Gilman \& Huebner, 2003). Such differences in perspectives among researchers, adults and adolescents about wellbeing conceptualizations has significant 
implications for assessment and intervention (Ben-Arieh et al., 2014; Bourke \& Geldens, 2007; Casas, 2011; Chaplin, 2009; Fattore et al., 2007). For example, school or positive education ${ }^{1}$ interventions $^{2}$ have often been unsuccessful potentially due to disparities between experts' and adolescents' notions (Bott et al., 2017; Cook, Kilgus, \& Burns, 2018). Understanding adolescents' meaning and sources of wellbeing is therefore a critical question worthy of empirical investigation. Although adolescents are willing and capable to contribute (Andresen et al., 2019; Fattore et al., 2007; Sarriera \& Bedin, 2017), extant wellbeing research has traditionally shown a bias towards adults. There is an inadequate understanding of what constitutes and promotes wellbeing for adolescents.

Wellbeing has been defined as individuals' evaluations and perceptions of the quality of their lives (Keyes, 2013), yet researchers have usually disregarded or discounted adolescents' perceptions regarding their own wellbeing (Casas, 2011). There are limited studies on adolescents' wellbeing, particularly in comparison to the extensive literature available on adults (Ben-Arieh, 2005; Blaskova \& McLellan, 2017; Camfield, Streuli, \& Woodhead, 2010; Casas, 2011). While there have been some emerging research efforts at obtaining adolescents' views of wellbeing in developed countries (Rees \& Dinisman, 2015), to date, no study has examined wellbeing conceptions of 11- to 13-year-olds in New Zealand. In addition, the scant empirical research in other countries is largely qualitative in nature (Chaplin, 2009; Crivello, Camfield, \& Woodhead, 2009; Fattore et al., 2007). Due to the absence of quantitative evaluation of adolescents' wellbeing perspectives, it is unknown how the components of wellbeing may be arranged in adolescents' perception (i.e., which components are the most or least significant). Whether adolescents' components of wellbeing vary as a function of socioeconomic status is also yet to be investigated empirically.

For the first time in New Zealand, the current study primarily aims to investigate the components of and pathways to wellbeing as per the perceptions of adolescents (aged 11 to 13) from low- and high-socioeconomic status utilizing a mixed-method approach. The readers will have a better understanding of how adolescents' notions are similar to or different than adults' and researchers' conceptions of wellbeing. Since adolescents are advisers of research work, understanding their perspectives may enable us to develop more accurate components of our assessment measures and frameworks of our cross-sectional and longitudinal studies. Understanding adolescents' conceptions may also help to enhance the overall precision, acceptability, and effectiveness of wellbeing interventions targeting this population. We will first address the existing literature regarding academic and lay perceptions of wellbeing.

\section{Research on conceptualizations and definitions of wellbeing.}

The concept of wellbeing is elusive. Presently there is no global or agreed upon definition of wellbeing (Baker, Green, \& Falecki, 2017; Diener \& Seligman, 2004). Several definitions of wellbeing exist in the academic literature (Diener, Scollon, \& Lucas, 2003; Hone et al., 2014) that differ, in part, due to the variations in researchers' philosophical tradition. Researchers have theorised wellbeing as having components of the hedonic approach, comprising positive emotions towards one's life (i.e., happiness, life satisfaction, and affect equilibrium), the eudaimonic approach, comprising

${ }^{1}$ Positive education means imparting wellbeing education in schools alongside academic education. 
positive psychological and social functioning, and the current holistic approach that integrates emotional/subjective, psychological, and social wellbeing (Keyes, 2013; Norrish, Williams, O'Connor, \& Robinson, 2013).

Informed by these approaches, many academic models of wellbeing have been proposed that denote different conceptualizations of wellbeing (Diener et al., 2010; Durie, 1985; Keyes, 2005; Renshaw et al., 2014; Ryff, 1989; Ryff \& Keyes, 1995; Seligman, 2011; Westerhof \& Keyes, 2010). For example, some components listed in Keyes (2005) model, namely social growth, positive affect, and personal growth, do not feature in Diener et al.'s (2010) model. Similarly, Seligman (2011) identified five components of wellbeing in his PERMA model (positive emotion, engagement, relationships, meaning and purpose, and accomplishment), whereas Huppert and So (2013) proposed 10 components of wellbeing (including positive relationships, positive emotions, self-esteem and emotional stability). One model of 12 positive psychology building blocks for adolescents, on the other hand, is composed of four core components of belief-in-self, belief-in-others, emotional competence, and engaged living (Renshaw et al., 2014). Compounding such academic disagreements, making a choice among wellbeing models may present educators, psychologists, and researchers with a dilemma.

There have been empirical attempts to define wellbeing with greater accuracy by examining lay conceptions of wellbeing (Anderson \& Graham, 2016; Chaplin, 2009; Fattore et al., 2007; Hone, Schofield, \& Jarden, 2015; Soutter, O'Steen, \& Gilmore, 2012). Research on the lay conceptualizations of wellbeing has been conducted with affluent Caucasian adults or late adolescents (Hone et al., 2015; Soutter et al., 2012). Hone et al. (2015) demonstrated that New Zealand adults conceptualize wellbeing as good mental health, physical health, good relationships, work-life balance, and feeling valued. While the methodology of this study was systematic, the sample was predominantly European. Soutter et al. (2012) found that having resources, being independent, relating well with teachers, functioning effectively in assessment-related activities, and striving towards scoring credits were reported as the most important for 17- to 21-year-olds' understanding of wellbeing.

More recently there has been a growth in qualitative studies on perceptions of children and adolescents (Rees \& Dinisman, 2015). In their study, Anderson and Graham (2016) asked 6- to 18year-olds to rank two pre-defined concepts of wellbeing. Although the authors found support for recognition and participation as important components, the study was limited by their chosen methodology as the survey format restricted choice to two academic concepts of wellbeing, and a free-response format was not employed to capture adolescents' views. Chaplin (2009) used an interview method and identified sports, hobbies, achievements, material things, and pets and people as what constitutes and promotes wellbeing of American adolescents (aged 8 to 18). Another qualitative study by Fattore et al. (2007) utilized task-oriented strategies to explore views of 8- to 15year-olds in Australia and reported themes of agency, feeling secure, and a positive sense of self, and concrete themes of relationships, material resources, home, and physical environment. These authors also highlighted the need to study variations in perceptions across socioeconomic groups. While the above studies were conducted in developed countries, Crivello et al. (2009) examined children's and adolescents' wellbeing components in developing countries (e.g., Ethiopia and Peru), 
some of which were being joyful, wearing clean clothes, and having electronic goods. Overall, the literature signifies that wellbeing is a comprehensive concept characterized by several components that may vary as a function of a person's experience, age, and country.

In the current study we perceive adolescent wellbeing as a multidimensional concept that integrates psychological, social, schooling, physical, spiritual, and demographic components. In the next section we move beyond conceptualizations of wellbeing and review the research on pathways to wellbeing.

\section{Pathways to wellbeing.}

Less attention has been paid to obtaining views of adolescents about ways to enhance wellbeing and involving them in the creation of promotional models and programs of wellbeing (Casas, 2011). In the context of wellbeing promotion of adolescents, the Geelong Grammar School's whole-school positive education model is focused on fostering positive purpose, positive relationships, positive emotion, positive health, positive engagement, and positive accomplishment within the school (Norrish, 2015). The Strath Haven Positive Psychology Curriculum program aims to strengthen relationships, meaning, positive emotions, and character strengths (Seligman, Ernst, Gillham, Reivich, \& Linkins, 2009), while a 10-session Wellbeing Promotion Program focuses upon building hope, strengths, gratitude, optimism, and kindness in schools (Suldo \& Savage, 2016). Public health messaging aimed to improving wellbeing has also come from government frameworks. For example, Aked, Marks, Cordon, and Thompson (2008) suggested Five Ways to Wellbeing: taking notice, being active, connecting with others, learning, and giving. Investigating pathways to wellbeing among New Zealand lay adults Hone et al. (2015) found physical activity, nurturing relationships, interests/hobbies, and eating healthily as the most frequently reported. An examination of New Zealand adolescents' perceptions of ways to improve wellbeing is warranted to add to the lack of existing empirical data on this topic, which could have meaningful theoretical implications and practical advantages for organizations and individuals working with adolescents.

\section{Importance of adolescents' wellbeing perceptions.}

Adolescents' understanding of wellbeing can inform the theory and application of wellbeing in schools. Adolescents' views may be useful in refining or validating researchers' models of wellbeing and enhance the precision with which wellbeing is assessed (Bourke \& Geldens, 2007). A greater understanding of adolescents' conceptualizations of wellbeing may also improve the efficacy of school interventions considering the "contextual fit" and "precision education" propositions (Cook et al., 2018; Horner, Blitz, \& Ross, 2014). Precision education supports the idea that the key components of interventions should be tailored to individuals' needs and perceptions (Cook et al., 2018). Horner et al. (2014) defined contextual fit as the match between components of an intervention and the needs and perceptions of those who experience the intervention. How well a program is received or valued in a certain setting, or the social validity/acceptability of school interventions is likely to depend on the opinions of adolescents who are directly affected by the program (Marchant, Heath, \& Miramontes, 2012). It is potentially misleading for researchers to define adolescents' wellbeing without considering adolescents' viewpoints in defining wellbeing. The present study 
attempts to address this gap by investigating adolescents' conceptualizations of wellbeing utilizing a prototype analysis methodology (Rosch, 1975).

\section{A prototype analysis perspective.}

Prototype analysis is a mixed-method approach that has been established as an effective method of analysis for natural language categories, such as happiness, fear (Fehr \& Russell, 1984), gratitude (Lambert, Graham, \& Fincham, 2009), forgiveness (Kearns \& Fincham, 2004), infidelity (Weiser, Lalasz, Weigel, \& Evans, 2014), love and commitment (Fehr, 1988), and wellbeing (Hone et al., 2015; Jarden, Sandham, Siegert, \& Koziol-McLain, 2018). This method assumes some components are more important or central to a concept, and others are less important or peripheral. In a prototype approach, thus, all components of a concept are not equally representative of that concept, contrary to a classical view where category membership is determined by necessary, sufficient, and fixed criteria (Rosch, 1975). A prototype approach helps in identifying a "fuzzy collection" (Lambert et al., 2009, p. 1195) of the central components of a concept (also called prototypes) rather than identifying critical components (Lambert et al., 2009, p. 1195). For a comprehensive review of the strategy, read Fehr (1988) and Kearns and Fincham (2004).

Driven primarily by this approach, this study has drawn inspiration from Hone et al.'s (2015) research. They demonstrated that wellbeing is prototypically organized in a sample of New Zealand teachers and lawyers. In addition, the current differences between different academic models of wellbeing indicates the components of wellbeing are not fixed (Hone et al., 2015) and "the boundaries of the notion of well-being are elastic" (Ben-Arieh et al., 2014, p. 3). Rosch (1975) listed two essential conditions of the prototype analysis method reflected in the current study: a) the participants should be able to list the features of the concept and reliably rate which components are more central to the concept, and b) the centrality rating of components should influence participants' perceptions of the concept.

\section{The present study.}

The main research question of the study was: What are the perceptions of New Zealand adolescents (aged 11 to 13 years) about the 1) components of wellbeing and 2) pathways to wellbeing? We also hypothesized that a) wellbeing will be prototypically organized in adolescents, and b) differing socioeconomic status will be associated with adolescents' perceptions of the centrality of the components. We subsequently examined whether New Zealand adolescents' perceptions aligned with popular academic models and New Zealand adults' conceptualizations of wellbeing.

\section{Method}

\section{Overview of studies.}

Three studies were conducted to address the above aims. In Study 1, participants listed the components and pathways regarding wellbeing in free-response format. In Study 2, a different sample of participants rated the centrality (or importance) of the components generated in Study 1. Study 3 tested the hypothesis that central components of wellbeing were related more closely to 
perceptions of wellbeing than the peripheral components on a third sample of adolescents. The effect of socioeconomic differences was examined in all three studies.

\section{Recruitment process for all studies and ethical considerations.}

The recruitment process involved emailing schools in Auckland, New Zealand, with a study invitation. We used convenience sampling technique for recruitment though preference was given to the school type (state intermediate schools with Years 7 and 8) and school socioeconomic decile. In New Zealand, school decile is a key measure of the school students' socioeconomic status. Decile 1 draws the highest proportion of students from low-socioeconomic backgrounds, whereas Decile 10 draws the highest proportion of students from high-socioeconomic backgrounds (Ministry of Education, 2018). Two state intermediate schools agreed to participate in the study: one Decile 1 and the other Decile 10. These schools were located in ethnically and socioeconomically diverse regions. The schools provided different classes for participant recruitment. From each class that was offered, we recruited only those students who assented to participate. There was no overlap in participants of the three studies, and the participants of all three studies were recruited from the same schools. The data for Study 1 was collected between 7 May and 6 June 2017, for Study 2 between 25 June and 28 June 2017, and for Study 3 between 27 July and 31 July 2017.

Ethical approvals for all the procedures and materials were obtained from the Auckland University of Technology ethics committee. A meeting was held with the principals of participating schools to inform them about the study aims. The potential participants and their parents were given separate sheets informing them about the study's aim, importance, and procedure 2 weeks prior to each study. The studies utilized anonymous surveys and involved minimal risk so parental consent was not sought; however, participants' assent was taken electronically before each study. A registration system was used to collect participants' demographic information and assent. Participation in the study was by voluntary inclusion only and the parents could withdraw their children from participating in the study, or the students could leave on their own. University-branded pens were given to all the participants of each study as incentives.

\section{Study 1: Free Listing and Compilation of Prototypic Wellbeing Components and Pathways to Wellbeing}

The aim of the first study was to compile a list of wellbeing components and aspects aimed at enhancing wellbeing. Participants were first asked to list as many wellbeing components as they could think of. Second, they were asked to list all the aspects they thought fostered their wellbeing (i.e., their pathways to wellbeing). Both the questions utilized an open-ended response format.

\section{Participants.}

The sample comprised 125 adolescents (65 boys and 60 girls) aged 11 (39\%), 12 (55\%) and 13 (6\%) from Year 7 (46\%) and Year 8 (54\%) from two Auckland schools. Thirty-eight percent of participants were from a low-decile school (48 from Decile 1) and 62\% from a high-decile school (77 from Decile 10). Approximately $53 \%$ of the sample was New Zealand European. The remaining participants 
were Māori (indigenous people, 11\%), Pacific Islanders (18\%), Asian (7\%), and African/Middle Eastern (4\%). Approximately $7 \%$ of participants indicated they were of mixed ethnicity.

\section{Procedure.}

The survey was managed in-person by the researcher within school hours. Participants followed a web link on their school computers to register for the survey and provided their demographic details and assent. Those who submitted the registration form could subsequently access the electronic survey presented on the SurveyMonkey platform. They were given the following verbal, and then on-screen, instructions in their respective schools (adapted from Fehr \& Russell, 1984, Study 6; Hone et al., 2015):

This is a study on what young New Zealanders of your age think of when they think of the word wellbeing. For example, if you were asked to list the components of fear, you might write: possible danger occurs, heart beats wildly, eyes open wider, the person runs as fast as they can. Similarly, if you were asked to write the components of sadness, you might write: becoming quiet and lazy, crying. In the current study, we are not interested in fear or sadness, but in the characteristics of wellbeing. Imagine that you are explaining the concept wellbeing to someone who does not know about wellbeing and answer the following question: What, in your opinion, are the components of wellbeing? There is no time limit. List as many as you can.

After the participants answered the above question, they answered an additional question on the same screen:

“What, in your opinion, enhances your wellbeing? Specifically, which factors in your life or particularly at your home, school, and society help in improving your wellbeing?"

\section{Analysis.}

A list of verbatim responses was prepared, only correcting for spelling. Adhering to the coding procedure outlined in Fehr (1988), two broad steps of analysis were undertaken, similar to prototype analysis research (Fehr \& Russell, 1984; Hone et al., 2015; Kearns \& Fincham, 2004; Lambert et al., 2009; Weiser et al., 2014). Note that these steps were assumed separately for components and pathways regarding wellbeing. The first step involved identifying and extracting monolexemic linguistic units which were distinct and easily recognizable, such as component responses "happy," and "joyful" and pathway responses "family" and "pets." When participants used a phrase, judgment was deemed necessary to decide whether a phrase conveyed one or multiple thoughts. For example, the responses "others don't put you down" or "joy in basic luxury such as running water" were judged to convey one thought and noted as individual linguistic units, whereas the responses "completing something or doing something right" and "having help when needed and treated well by others" were judged to convey two thoughts and retained as distinct components. Phrases were only separated in terms of meaning, the unit largely remained original. 
The linguistic units preceded by attributive words, such as "lots of energy" were coded as a single item. For data organization, identical units were combined as one and their frequencies were noted. For example, all "games" responses were written only once in the list with the frequency besides them. An elaborate reading of the text with a combined usage of word-frequency tools (tools that identify the number of times each word occurs in the text) facilitated unit identification. As an outcome, a total of 551 component linguistic units were reduced to 203 after deleting duplicates, yielding an average of 4.40 components per participant (approximately 4.60 for high-decile school participants and 4.00 for low-decile school participants). For pathways, 565 linguistic units were reduced to 188 with each participant generating an average of 4.52 linguistic units (4.54 for lowdecile group and 4.50 for high-decile group).

After mapping out the linguistic units and preparing separate lists for components and pathways, the units were allocated to a category. Single unique words were formed into independent categories. For example, the linguistic unit "being happy" was allocated to the category "being happy." Items similar in grammatical form and conveying the same meaning were classified under one category. Classifying similar units together aided in avoiding redundancy. For example, "being happy" and "happiness" were treated as a single component category. Also, words with similar meaning such as "cheerful" and "joyful" were assigned to the same category of "being happy." Concerning pathways, "my pets," "playing with my dog," and "having animals" were categorized under the pathway category of "pet ownership and attachment." Responses such as "beach" and "rain and sunlight make me feel warm and cozy" were collapsed into the category "nature." Responses were classified verbatim to depict adolescents' exact thoughts and maintain the authenticity of responses. For example, the unit "belief in your abilities" was categorized as "belief in your abilities." Responses such as "being loved" and "trying new things" were categorized as reported.

Besides following a conservative categorizing approach, a balance was maintained by combining similar units and keeping the non-similar ones separate. For instance, responses about pathways that included activities such as "dance," "cooking," and "reading" were headed under the category "hobbies/doing things that interest you." Although an activity dance may potentially enhance wellbeing, a broad categorizing approach was applied for locating key breadth strategies from an application point of view. However, instead of collapsing pathway responses such as "Netflix," "computer games," and "watching movies" to the category of hobbies/doing things that interest you, a new category of "digital entertainment" was created. Some components necessitated examination of the adjoining words in the response. For example, the unit "healthy" was judged to be a part of the category "good physical health" as it followed or preceded the words with a physical dimension such as "active and healthy" and "being healthy and fit." We have published the raw data online so readers can examine our judgments (Bharara, Duncan, \& Jarden, 2018a, 2018b).

Since the participants were schoolchildren, an estimated $50 \%$ of linguistic units were either associated semantically or linguistically and were classed to the same component or pathway category. Judgment calls were validated by the third and fourth authors of this study and any discrepancies were resolved through discussion. Various responses were idiosyncratic, i.e., 
mentioned by only one participant. Any component category that was listed by less than $2 \%$ of the sample (39 components) was discarded from further analysis to reduce the burden on Study 2 participants (who had to rank the centrality of these components). Similarly, pathway categories listed by less than $2 \%$ of the sample (47) were excluded from further analysis (Hone et al., 2015).

\section{Results.}

Table 1 shows the 26 components of wellbeing sorted by Study 2 centrality ratings. The table displays the frequency of components (the number of times each component occurred in the text) and the participants' listing percentage of the components. Note that how frequently each component occurred in the text was different compared to the percentage of participants that mentioned a component. More than $70 \%$ of the sample listed being happy as a component of wellbeing, followed by being kind/helpful (35\%), and good physical health (34\%). Being focused (2.4\%), contentment/peace $(3.2 \%)$, and being grateful $(3.2 \%)$, were the least listed components. Table 1 also depicts the percentage of participants that listed each component from low- and high-decile schools. Both socioeconomic groups listed being happy as their most frequently reported component of wellbeing. While the low-decile school participants listed being kind/helpful second (56\%), the component moved into third place for the high-decile school's participants (22\%). 
Table 1

Study 1 Wellbeing Components Arranged by Study 2 Centrality Ratings

\begin{tabular}{|c|c|c|c|c|c|c|}
\hline \multirow[b]{2}{*}{ Component } & \multirow{2}{*}{$\begin{array}{r}\text { Study } 1 \\
\text { Frequency }\end{array}$} & \multicolumn{3}{|c|}{ Listing percentage } & \multicolumn{2}{|c|}{ Study 2} \\
\hline & & $\begin{array}{l}\text { \% low } \\
\text { decile }\end{array}$ & $\begin{array}{r}\% \text { high } \\
\text { decile }\end{array}$ & $\begin{array}{r}\% \text { total } \\
\text { participants }\end{array}$ & $\begin{array}{r}\text { Centrality } \\
\text { rating }\end{array}$ & $\begin{array}{l}\text { SD } \\
\text { (s) }\end{array}$ \\
\hline Being happy & 130 & 70.8 & 74.0 & 72.8 & 9.03 & 1.51 \\
\hline Enjoyment/having fun & 19 & 20.8 & 7.79 & 12.8 & 8.80 & 1.53 \\
\hline Feeling good & 22 & 14.7 & 19.5 & 17.6 & 8.65 & 1.48 \\
\hline Feeling safe & 20 & 10.4 & 13.0 & 12.0 & 8.63 & 1.76 \\
\hline Good mental health & 14 & 8.33 & 11.7 & 10.4 & 8.47 & 1.73 \\
\hline Being kind/helpful & 54 & 56.4 & 22.1 & 35.2 & 8.36 & 1.89 \\
\hline Belief in your abilities & 7 & 4.12 & 6.49 & 5.60 & 8.25 & 1.74 \\
\hline Being respectful & 19 & 27.0 & 5.19 & 13.6 & 8.23 & 1.93 \\
\hline Being respected/encouraged & 9 & 6.25 & 6.49 & 6.40 & 8.21 & 1.72 \\
\hline Positive attitude/optimism & 11 & 2.08 & 11.7 & 8.00 & 8.17 & 1.79 \\
\hline Self-confidence & 7 & 2.08 & 7.79 & 5.60 & 8.12 & 1.94 \\
\hline Good values & 5 & 2.08 & 3.90 & 3.20 & 8.07 & 2.04 \\
\hline Being grateful & 4 & 2.08 & 3.90 & 3.20 & 8.02 & 2.06 \\
\hline Good relationships & 26 & 12.5 & 13.0 & 12.8 & 7.95 & 2.29 \\
\hline Excitement & 18 & 12.5 & 15.6 & 14.4 & 7.95 & 1.96 \\
\hline Good physical health & 50 & 22.9 & 40.3 & 33.6 & 7.80 & 2.37 \\
\hline Good & 21 & 16.7 & 14.3 & 15.2 & 7.77 & 2.00 \\
\hline Success/achievements & 7 & 4.12 & 6.49 & 5.60 & 7.75 & 2.27 \\
\hline Feeling calm and relaxed & 9 & 6.25 & 6.49 & 6.40 & 7.74 & 1.90 \\
\hline Contentment/peace & 4 & 0.00 & 5.19 & 3.20 & 7.70 & 1.92 \\
\hline Sense of satisfaction & 9 & 2.08 & 9.09 & 6.40 & 7.15 & 2.08 \\
\hline Energetic & 15 & 10.4 & 13.0 & 12.0 & 7.12 & 2.46 \\
\hline Being focused & 3 & 0.00 & 3.90 & 2.40 & 6.75 & 2.33 \\
\hline Being expressive & 6 & 4.12 & 5.19 & 4.80 & 6.57 & 2.34 \\
\hline Comfort/being wealthy & 8 & 2.08 & 7.79 & 5.60 & 6.11 & 2.99 \\
\hline Absence of sadness & 8 & 0.00 & 9.09 & 5.60 & 5.58 & 2.98 \\
\hline
\end{tabular}

Figure 1 shows a word cloud that illustrates the 37 pathway categories of wellbeing. The size of the text in the figure is based on the participants' listing percentage. More than half of the adolescents thought that positive family relationships $(60 \%)$ and positive friendships $(55 \%)$ enhance their wellbeing. While $34 \%$ of the participants listed physical activity/sport, 30\% listed hobbies/doing things that interest you as important pathways to wellbeing. Other important pathways were nature $(17 \%)$, digital entertainment (16\%), pet ownership and attachment (14\%), being kind/helpful (14\%), socializing, and being around positive people (13\% each). The mean of the participants' listing 
percentage was $10.8 \%$. Both socioeconomic groups frequently listed positive family relationships, positive friendships, and physical activity/sport as pathways to wellbeing.

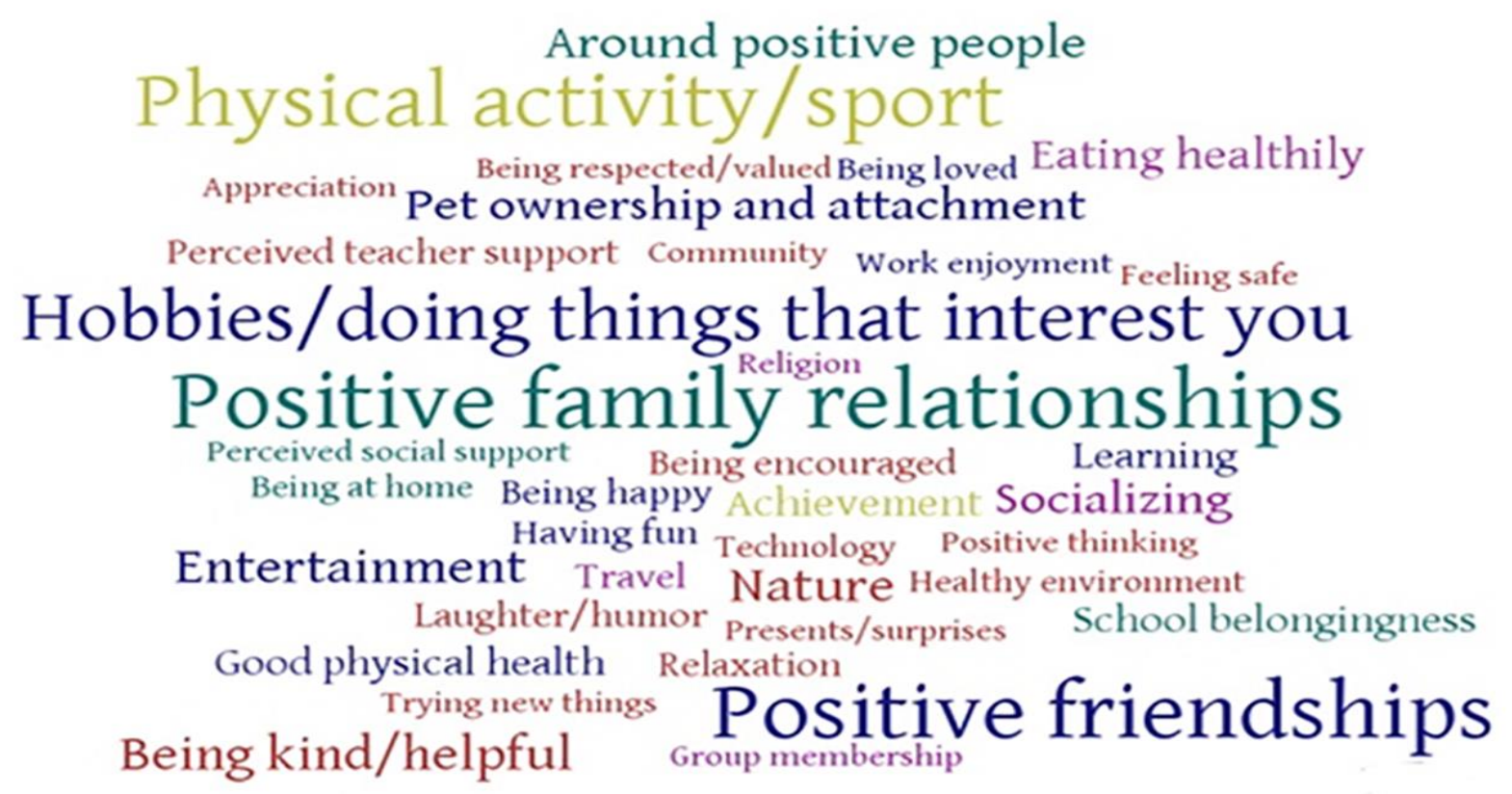

Figure 1. Adolescents' pathways to wellbeing.

\section{Discussion.}

Many responses were reduced to a limited number of components and pathways comparable to the results of other prototype studies (Hone et al., 2015; Kearns \& Fincham, 2004; Weiser et al., 2014). Three components appeared most frequently in the text: being happy, being kind/helpful, and good physical health. Only $5.6 \%$ of adolescents in the current study listed comfort/being wealthy as a component of wellbeing. These results are partially different to prior studies (Chaplin, 2009; Fattore et al., 2007). Another important observation was adolescents' listing of "feeling safe" in the present research, and in previous research (Anderson \& Graham, 2016; Fattore et al., 2007). Components of wellbeing not discussed in the current academic models were evident, for example, being kind/helpful, good physical health, feeling safe, and enjoyment/having fun. The non-appearance of these components in academic models suggests that adolescents may have a different characterization of wellbeing.

Both socioeconomic groups frequently listed being happy, good physical health, and being kind/helpful as components of wellbeing. However, the listing percentages of some components varied. For example, the low-socioeconomic group mentioned good physical health considerably less than the high-socioeconomic group, whereas the high-socioeconomic group did not list enjoyment/having fun as much as the low-socioeconomic group. Hence, some influence of socioeconomic status in the recall of wellbeing components was evident, which was further tested in Study 2. 
Overall, the prototype of wellbeing includes beliefs, feelings, and actions. Participants listed cognitive states, mindsets, and beliefs such as contentment/peace, belief in your abilities, and positive attitude/optimism. Interestingly, actions were perceived as components of wellbeing such as being kind/helpful. Emotive states and feelings were also listed by the participants such as being happy and feeling good. Of importance is the holistic amalgamation of psychological, social, physical, spiritual, and demographic aspects in adolescents' perception of wellbeing, similar to our understanding of the concept. This understanding is also comparable to Durie's (1985) Māori model of wellbeing, Te Whare Tapa Whā, where he compares Hauora (wellbeing) with four walls of a house (whare) comprising four dimensions namely taha tinana (physical health), taha hinengaro (mental health), taha wairua (spiritual health), and taha whanau (family).

The most frequently listed pathway to wellbeing was positive family relationships, followed by positive friendships and physical activity/sport, all of which are social and physical components. These findings resonate with wellbeing models such as the Geelong Grammar School model (Norrish et al., 2013), as well as previous research with adolescents on pathways to wellbeing (Chaplin, 2009). The government frameworks that identify Five Ways to Wellbeing (Aked et al., 2008; Mental Health Foundation of New Zealand, 2018) are also reflected in the current study in the following ways: connect (similar to positive friendships and positive family relationships), give (similar to being kind/helpful), be active (similar to physical activity/sport), keep learning (similar to learning), and take notice (similar to nature). Surprisingly, adolescents did not list some pathways to wellbeing (e.g., mindfulness and gratitude) that have been demonstrated to have a positive effect on wellbeing (Norrish, 2015). This omission suggests adolescents were uninformed about these pathways in the current study, and they seemed to be more familiar with tangible pathways to wellbeing (e.g., sports, pets), which are clear-cut and straightforward to their understanding, rather than intangible pathways to wellbeing (e.g., mindfulness) which are abstract.

\section{Study 2: Centrality Ratings of Wellbeing Components}

The objective of Study 2 was to determine the centrality of Study 1 components. If a concept possesses a prototypical structure, the individuals should not only be able to list the components of a concept but also rate how central or peripheral each component is to their concept of wellbeing with substantial agreement on these ratings. A different group of participants, thus, judged how important or unimportant each component previously identified in Study 1 was to their own concept of wellbeing, and their judgments were examined for agreement. The impact of socioeconomic decile on wellbeing components' centrality ratings was also examined.

\section{Participants.}

The sample comprised 122 intermediate school students (65 boys and 57 girls) from Year 7 (39\%) and Year 8 (61\%), aged 11 (32\%), 12 (57\%) and 13 (11\%) from two schools in Auckland. Thirty-four percent participated from a low-decile school (42) and 66\% (80) from a high-decile school. Approximately 56\% were of European background, 13\% were Māori, and 12\% were Pacific Islanders. Some participants indicated that they were Asian (7\%) or African (2\%). About $10 \%$ of participants reported that they were of mixed ethnic background (including Māori European, Pacific 
Māori or Pacific European). The demographic characteristics of these participants were comparable to the Study 1 sample.

\section{Procedure.}

Participants filled in the registration details and accessed the online survey. Participants were given the following verbal and on-screen instructions within the school hours (adapted from Hone et al., 2015):

In a previous study, we asked students of your school level to list the components of wellbeing that came to their mind when they thought of the word wellbeing. On the next page, you will read the responses of the students in our earlier study in alphabetical order. After reading each one, please rate how important or less important you think each component is to your understanding of wellbeing by clicking a number between 0 (an extremely poor component of wellbeing) to 10 (an extremely good component of wellbeing).

\section{Analysis.}

Two measures provided evidence for the reliability of the means of ratings of 26 components. First, the intra-class correlation coefficient was calculated, which is equivalent to the mean of all possible split-half correlations of the 122 judges with respect to 26 components (ICC $=.910, p<.000$, average measures), which showed excellent inter-rater reliability. Second, the data matrix was flipped (26 components were treated as cases and 122 participants as items) which also indicated an exceptionally high internal consistency of the ratings $(\alpha=0.96)$. Spearman's rank correlation coefficient was computed to examine the relationship between Study 1 listing percentage and Study 2 centrality ratings. A Mann-Whitney test was also conducted to examine whether school decile influenced the mean centrality ratings of the 26 components.

\section{Results.}

Table 1 shows the mean centrality ratings of the components in descending order. The correlation between centrality ratings in Study 2 and participants' listing percentage in Study 1 was moderately positive ( $r s(r h o)=0.522, p<.01$ one-tailed). Nearly half of the components were listed frequently and given high centrality ratings (e.g., being happy), whereas some components that were frequently mentioned in Study 1 received a relatively lower centrality rating in Study 2 (e.g., good physical health). Figure 2 shows a scatterplot graph illustrating the relationship between Study 1 and Study 2 component rankings. For example, feeling good was ranked third in Study 2 but fourth in Study 1.

Significant differences exist in mean centrality ratings of five components as a function of school decile. Specifically, individuals in the low-socioeconomic group considered the following components as more central for wellbeing than the high-socioeconomic group: being focused (8.00, $7.00, p=0.005 r=0.260)$, comfort/wealthy $(7.50,6.00, p=0.004, r=0.260)$, good physical health $(10.00,8.00$, $p=0.00100, r=0.300)$, good values $(10.00,8.00, p=0.005, r=0.250)$, and success/achievements $(9.00,8.00$, $p=0.004, r=0.260)$. Good physical health was associated with a medium effect size. The high- 
socioeconomic group did not consider any component more central than the low-socioeconomic group.

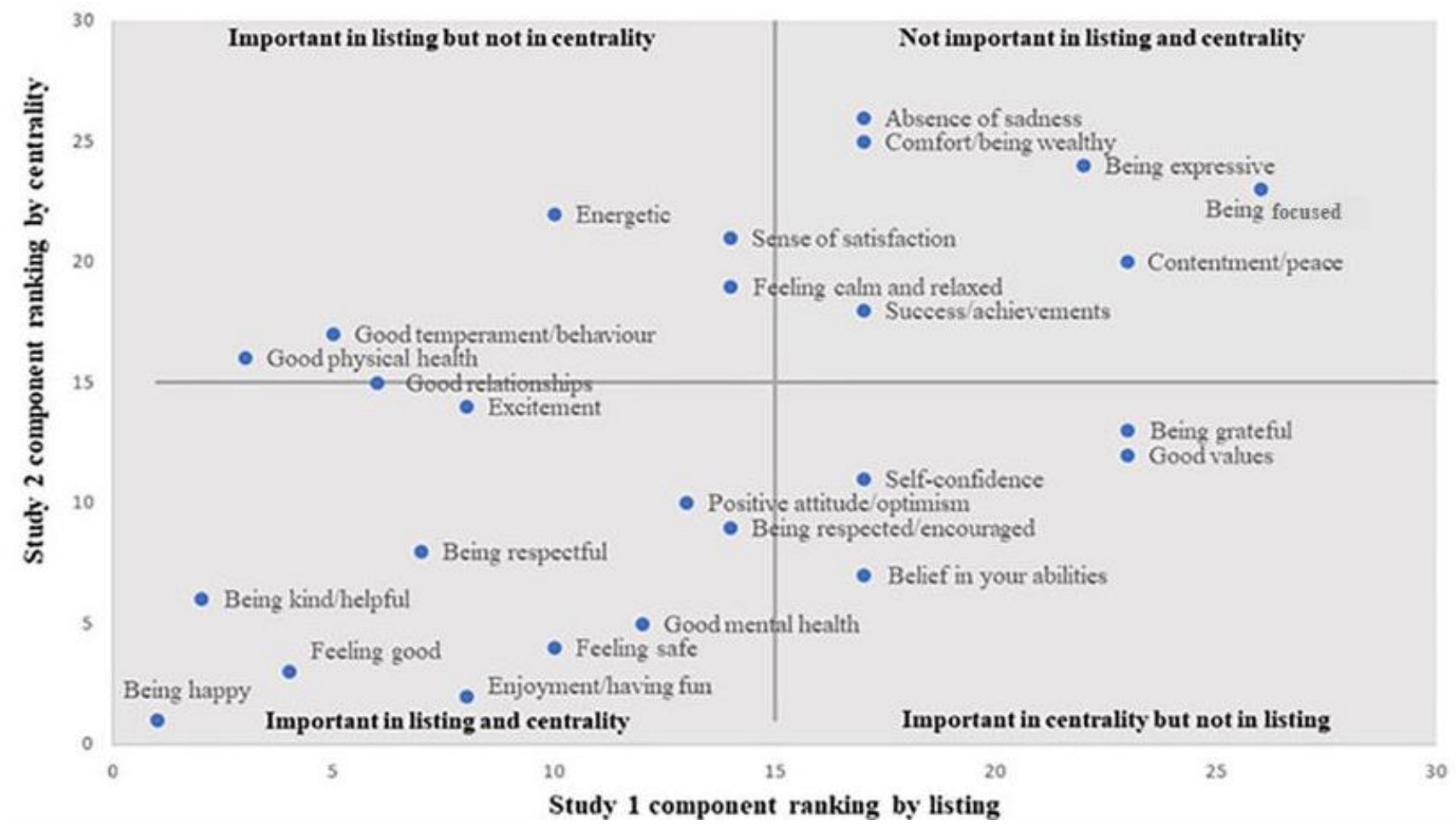

Figure 2. Components' ranking correlation between Study 1 (listing phase) and Study 2 (centrality phase)

\section{Discussion.}

Adolescents perceive some wellbeing components as more central than others, thereby fulfilling the first condition for ascertaining a concept's prototypical structure. For example, feeling safe, enjoyment/having fun, and being kind/helpful received higher ratings than the components comfort/being wealthy and sense of satisfaction, which are less prototypical of wellbeing. While research has reported economic circumstances and material possessions as a key domain of wellbeing for American adolescents (Chaplin, 2009; Land, Lamb, \& Mustillo, 2001) and Australian adolescents (Fattore, Mason, \& Watson, 2009), it is noteworthy that possessing material things was less significant for our sample of New Zealand adolescents, that is, comfort/being wealthy was observed to be a peripheral component.

Some disparities were apparent in Study 1 and Study 2 data that could be attributable to the distinct cognitive processes associated with listing and rating components (Fehr, 1988). Listing items requires different heuristics than rating a predetermined list, which is consistent with previous prototype research (Kearns \& Fincham, 2004). Finally, school decile significantly impacted the ratings of five components; however, the differences in perceptions were not significant for 21 components. Thus, adolescents with different socioeconomic status mostly have parallel perceptions 
about wellbeing components with unique variations regarding certain aspects, such as good physical health.

\section{Study 3: Impact of Components' Centrality on Perception of Wellbeing}

The first two studies fulfilled the first condition of prototype analysis procedure. Study 3 was a validation study conducted to test the second and final condition: Does components' centrality have an impact on participants' perceptions of wellbeing? We hypothesized that (if wellbeing is prototypically organized) central components would be perceived as more representative of the concept of wellbeing than peripheral components. The interaction between school decile and component centrality on the perception of wellbeing was also tested. To address the aim, a different sample was presented with descriptions of two imaginary persons depicting the central and peripheral components of wellbeing identified in Study 2.

\section{Participants.}

Participants were 114 New Zealand adolescents (60 boys and 54 girls) from a low-decile (37\%, 42) and high-decile $(63 \%, 72)$ Auckland intermediate school. Approximately $41 \%$ of the participants were from Year 7 and 59\% from Year 8. Participants were of different ethnic backgrounds including Māori (12\%), Pacific Islander (17\%) and New Zealand European (55\%), Asian (11\%), and African/Middle Eastern (2\%). The remaining identified themselves as of mixed ethnicities (3\%). Age of the participants was $11(28 \%), 12(58 \%)$, and $13(14 \%)$ years. This sample had similar demographic characteristics to the previous samples.

\section{Procedure.}

In using central and peripheral components of wellbeing in writing the scenarios, a procedure of median split was applied to divide the Study 2 centrality ratings into central and peripheral categories consistent with other prototype analysis studies. Centrality ratings higher than 7.98 (median of the 26 ratings) were considered central, and ratings lower than this value were considered peripheral (see Table 1). Even though essential for the current study, the authors acknowledge that centrality is continuous and such demarcation is artificial (Lambert et al., 2009). Based on the median, the participants were presented with two imaginary scenarios describing central (Sam's scenario) and peripheral (Laura's scenario) components of wellbeing in a random manner. Mean centrality scores of central and peripheral components were 8.38 and 7.22 respectively.

Sam's wellbeing: Sam is happy and feels good. He is known for his kindness and helpful nature. When he is at school, he believes in his abilities to accomplish his set goals. When he is not at school, he engages in fun activities that he likes for the sake of his enjoyment. In general, he feels emotionally and physically safe at his school and at his home. What's more, his school counsellor recently informed him that he has good mental health.

Laura's wellbeing: Laura is energetic. She does not feel sad. Being expressive by nature, she likes interacting with her classmates during class discussions. She experiences a 
sense of satisfaction when she focuses on her school work. Although she is from a wealthy family and leads a comfortable life, she finds contentment and peace in life's small blessings.

Participants were instructed to rate how closely each scenario matched with their concept of wellbeing by clicking a number on an 11-point scale $(0=$ extremely poor match to $10=$ extremely good match).

\section{Analysis.}

A generalized linear mixed model was carried out to quantify the associations of centrality and centrality $\times$ decile with perceptions of wellbeing. Since scale variables were utilized with the dependent variable being numeric, the probability distribution was normal. Identity link function was used because the distribution was left-skewed. The analyses were conducted using IBM SPSS Statistics 24.0.

\section{Results.}

The central scenario (Sam's mean $=8.00$ ) was rated higher than the peripheral scenario (Laura's mean $=7.26)$. The association between centrality and scenario selection was statistically significant $(0.737$; CI $0.324,1.150 ; p=0.001)$. The Decile $\times$ Centrality (central or peripheral) interaction was also significant $(1.204 ;$ CI $0.116,2.293 ; p=0.030)$. In other words, the central scenario was more closely associated with the representation of wellbeing than the peripheral scenario. The association between the selection of the scenarios and component centrality was moderated by school decile. Table 2 shows the descriptive statistics for the two scenarios.

Table 2

Descriptive Statistics for the Imaginary Wellbeing Scenarios as per School Decile

\begin{tabular}{llccccc}
\hline $\begin{array}{l}\text { School } \\
\text { decile }\end{array}$ & Scenario & $\mathrm{N}$ & $\mathrm{M}$ & $\mathrm{SD}$ & $\mathrm{Md}$ & $\begin{array}{c}\text { Interquartile } \\
\text { range }\end{array}$ \\
\hline $\begin{array}{l}\text { High } \\
\text { decile }\end{array}$ & $\begin{array}{l}\text { Sam (central) } \\
\text { Laura } \\
\text { (peripheral) }\end{array}$ & 72 & 8.25 & 1.42 & 8.00 & 1 \\
& $\begin{array}{l}\text { Sam (central) } \\
\text { Low decile }\end{array}$ & 42 & 7.57 & 2.66 & 9.00 & 5 \\
& $\begin{array}{l}\text { Laura } \\
\text { (peripheral) }\end{array}$ & 42 & 7.60 & 2.27 & 7.50 & 4 \\
\hline
\end{tabular}

\section{Discussion.}

Our findings suggest that wellbeing is prototypically organized in adolescents. Comparisons of the medians in Table 2 also show that both low- and high-socioeconomic groups rated the central scenario higher than the peripheral scenario. Because socioeconomic decile moderated the 
relationship between selection of the scenario and centrality, it seems apparent that central components of wellbeing and decile-specific perceptions are not mutually exclusive.

\section{General Discussion and Implications}

This is one of the first studies to systematically determine 11- to 13-year-olds' perspectives of components and pathways regarding wellbeing via prototype analysis and examine the influence of socioeconomic decile on these perceptions. The findings may be a guide for those engaged in the assessment and promotion of adolescents' wellbeing in schools.

\section{Is Wellbeing Prototypically Organized in Adolescents?}

Our study finds that wellbeing is prototypically organized in adolescents. Participants could freely list and rate wellbeing components, and components' centrality significantly affected the perception of wellbeing. Hence, the research fulfilled the two conditions stated by Rosch (1975) in demonstrating a concept's prototype structure. This finding extends upon a body of work with New Zealand workers that is evidence of the prototypical structure of wellbeing (Hone et al., 2015; Jarden et al., 2018). Having a prototype structure of wellbeing suggests wellbeing assessment should take into regard a "fuzzy" (Lambert et al., 2009, p. 1195) presence or absence of central components, instead of requiring components with necessary and sufficient criterion.

\section{Do Adolescents' Perceptions of Wellbeing Components Correspond with Academic Models and New Zealand Adults' Conceptualizations?}

Since wellbeing is prototypically structured, adolescents' wellbeing conceptualizations include central components (e.g., being happy) and peripheral components (e.g., contentment/peace). It is noteworthy that adolescents' perceptions of central components of wellbeing comprising being happy, enjoyment/having fun, feeling safe, and being kind/helpful are quite distinct compared to New Zealand adults' wellbeing perceptions of good physical health, work-life balance, feeling valued, and good relationships. This finding signifies that elements that are desirable for adults may potentially not be desirable for adolescents. Therefore, wellbeing practitioners should be careful about the selection of elements of their assessment measures and interventions for adolescents (Marchant et al., 2012).

Results were assessed to examine how the central components are aligned with commonly used academic models, which demonstrated partial alignment. Adolescents' prototype of wellbeing is wide ranging (including emotions, behaviors, and cognitive states), and wellbeing experts have also shown consensus over the multidimensional nature of wellbeing (Huppert \& So, 2013). Regarding the components of wellbeing, however, some differences were observed. While some central components correspond to the researchers' definitions of wellbeing, others are recognized by researchers as correlates of wellbeing rather than as components. For example, in terms of similarities components such as being happy and feeling good relate to the positive affect/emotion dimension included in academic models (Huppert \& So, 2013; Keyes, 2005; Seligman, 2011). In contrast components such as being kind/helpful do not appear as components in academic models but have been shown to correlate positively with wellbeing (e.g., Layous, Nelson, Oberle, Schonert- 
Reichl, \& Lyubomirsky, 2012 studied kindness and wellbeing). Likewise, there is no exclusive focus on components feeling safe and enjoyment/having fun in wellbeing models irrespective of their unique presence in government frameworks of wellbeing (Canadian Institute for Health Information, 2009; Education Review Office, 2015a), and in empirical research with adolescents (Fattore et al., 2007). Adolescents also mentioned "being respected/encouraged" and "being respectful" as components of wellbeing in the current study, mirroring the results of Anderson and Graham (2016). The central component belief in your abilities is present in only one model of adolescent wellbeing (Renshaw et al., 2014). Overall, current models do not fully address what adolescents perceive to be wellbeing.

Some aspects normally observed in academic models such as meaning and purpose (Diener et al., 2010; Huppert \& So, 2013; Keyes, 2005; Seligman, 2011) were not listed by adolescents, even using their own language and terminology. Furthermore, while adolescents stated some behaviors as components of wellbeing (e.g., being kind and helpful and being respectful), most measures of wellbeing are cognitive and emotional, and hardly any ask about behaviors. Therefore, we suggest formulating a broader definition of wellbeing customized to the adolescents' perspectives, as outlined in this research, may be useful (comprising components omitted from academic models, such as enjoyment/having fun, feeling safe, being kind/helpful, being respected, and being respectful). By suggesting a broader definition we do not imply that experts disregard their own judgments. Instead, we suggest adolescents' perceptions of wellbeing identified in the current study may help inform researchers' models, which may also clarify the understanding of the concept of wellbeing for researchers.

\section{How Do Adolescents' Perceptions of Pathways to Wellbeing Correspond with Current Research and Academic Models?}

The most frequently listed pathways to wellbeing identified in this study build upon extant evidence. Positive relationships, physical activity, engaging in hobbies, and being kind/helpful are indispensable aspects of the current wellbeing promotion models and programs (Aked et al., 2008; Norrish, 2015; Suldo \& Savage, 2016). These results also correspond to the New Zealand workers' prototype research and research with adolescents (for a review see Chaplin, 2009; Hone et al., 2015). Eating healthily and socializing activities are significant aspects of the positive health and relationships domains of the Geelong Grammar School positive education model (Norrish, 2015) while the pathway pet ownership and attachment was also found in previous research (Chaplin, 2009). Interestingly, between 12 and 17\% of 11- to 13-year-olds listed nature, being around positive people, and digital entertainment as ways to improve wellbeing. Government promotional wellbeing framework has given importance to some of these aspects such as nature (Aked et al., 2008), whereas popular promotional models are less likely to emphasize the aspects pet ownership and attachment, nature, being around positive people, and digital entertainment. Research suggests contact with nature, including bush-walks and enjoying a day at the beach, enhances mental wellbeing of adolescents (Sarriera \& Bedin, 2017). Research on effects of digital entertainment on adolescents in mixed. Previous researchers have criticized the use of digital entertainment for adolescents; however, positive psychology researchers have focused on the beneficial effects of digital entertainment (e.g., exposure to programs depicting positive behaviors) on adolescents (De 
Leeuw \& Buijzen, 2016). Similarly, owning pets is beneficial for wellbeing of adolescents (Purewal et al., 2017). Overall, the pathways digital entertainment, pet ownership and attachment, being around positive people, being kind/helpful, and nature represent useful targets for adolescents' wellbeing promotion in the future.

\section{Does Socioeconomic Status Influence Adolescents' Wellbeing Perceptions?}

Socioeconomic status influences adolescents' perceptions of wellbeing. Both groups showed similar perceptions in the listing phase. However, significant differences were observed in the perceptions in the rating phase. This result indicates wellbeing perceptions of adolescents with different socioeconomic standing are broadly similar, but differences exist in the value given to certain components. For example, the low-socioeconomic group considered five components (including comfort/being wealthy, and success/achievements) of 26 as more important for wellbeing than the high-socioeconomic group. Differences in ratings may have surfaced due to adolescents' diverse socioeconomic status, culture, or overall culture of the school. Additionally, socioeconomic status moderated the relationship between centrality and perception of wellbeing. Consequently, socioeconomic groups' unique perceptions should be combined with adolescents' general perceptions in understanding their idea of wellbeing.

\section{Other Insights and Implications}

The examination of adolescents' freely listed responses identified interesting insights regarding their understanding of wellbeing. Firstly, 98\% of adolescents listed components relevant to the field of wellbeing and only $2 \%$ did not respond or listed aspects unrelated to the concept of wellbeing (as conceputalized by academic researchers). This study demonstrates adolescents' awareness of the concept of wellbeing-specifically, a considerable number of components (551) and pathways to wellbeing (565) were listed. Adolescents mentioned relatively tangible pathways such as family, peers, sports, and pets rather than abstract constructs such as mindfulness. While Norrish (2015) explains the lack of consideration of internal dimensions as adolescents' occasional "narrow thinking" and their focus on "material possessions" (p. 47), the present study shows adolescents' appreciation of deeper aspects such as nature and being kind/helpful. It is possible that adolescents are engaged in mindful activities but cannot give a name to the mental state due to lack of instruction.

Similarly, adolescents listed 14 more pathways than components demonstrating a greater awareness of the ways to foster wellbeing than of the concept of wellbeing. Whether that awareness is due to adolescents' interest and curiosity in enhancing wellbeing is largely unknown. Possibly, the notion of a component is more abstract than practical ways to foster wellbeing. Awareness reasons could vary, but some effortless awareness at an intuitive level of recognition is evident. Such "intuitive recognition" of the concept "may not be perfect, even though essential before testing or clarifying" (Cloninger, 2004, p. 8) meaning of the concept. Further empirical research is required to support the notion of intuitive understanding of wellbeing among adolescents.

Secondly, adolescents demonstrated some overlapping perceptions of the aspects that research $\underline{\text { suggests define and improve wellbeing. Certain components of wellbeing were also listed as }}$ 
pathways to wellbeing such as good physical health. The pathway-component overlap suggests that adolescents are either confused about the ideas of attribute and promotion to detect differentiation between the two, or they suppose a relation between aspects that define versus improve wellbeing. The second assumption has some empirical support (Chaplin, 2009). The results show components mentioned dually varied in frequency. For example, good physical health was listed frequently as a component but less frequently as a pathway. The variation in frequency might theoretically point to the possibility that adolescents are rather perceptive in discerning the difference between two intricate concepts. They listed a variety of responses that are characteristic of pathways and components (i.e., some of their pathways were incongruent with their own conception of wellbeing); however, they also showed some overlap. Thus, in schools, educators may consider promoting the central components of wellbeing not mentioned as pathways (e.g., gratitude).

Finally, adolescents' perceptions of wellbeing vary broadly. Though it is noticeable that some components and pathways were collectively stated by a high percentage of adolescents, no component or pathway of wellbeing was mentioned universally. The variability in responses reflects the distinctive characteristics or experiences influencing wellbeing perceptions. Hence, in the future, it will be valuable to consider adolescents' unique worldview together with the commonly perceived aspects of wellbeing. Parallel to the UNESCO (2004) curriculum differentiation approach where a curriculum is modified to match the learning needs of an individual, assessment measures and positive education practices ought to be personalized to fit wellbeing perceptions of adolescents, to pave the way for more precision in application of wellbeing (Cook et al., 2018; Horner et al., 2014).

\section{Limitations and Future Directions}

An open-ended survey was utilized for collecting qualitative data from many individuals at the same time. It is possible the writing ability of some participants affected the length and quality of their responses. Nevertheless, the researcher ensured participants understood the questions and participants were also free to ask for clarification. Secondly, the findings are limited by the subjective opinions of participants and researchers. For example, the coding of responses was subjective, and how one individual perceives a component of wellbeing may differ from another individual. Thirdly, the effect of ethnicity on adolescents' wellbeing perceptions could not be examined. An important direction for future research, therefore, is to investigate how adolescents' awareness of wellbeing differ across culture. Finally, we recognize that the sample size of low-decile group was relatively smaller than the high-decile group in all three studies (e.g., Study $1 n=48$ for low-decile group and $n=77$ for high-decile group) which may have potentially underrepresented lowsocioeconomic individuals' views. Taking the sample size into account, future research could assess low-socioeconomic group perceptions using a larger sample.

The literature on adolescents' perceptions of wellbeing is relatively inadequate and recent. The present study provides preliminary evidence about the variation in adolescents' prototype of wellbeing as a function of socioeconomic status. It is essential that further research examines the stability of adolescents' perspectives of wellbeing across countries and also investigates changes over time. As Fehr (1988) posited, it is likely that the prototypic features of a concept may vary with different populations, but the prototypical structure of a concept remains. Another useful direction 
for future research would be to study adolescents' perceptions of components of wellbeing (e.g., enjoyment) and the extent to which adolescents' prototype of wellbeing matches with an individual's representation of wellbeing.

\title{
Conclusion
}

This study contributes to an under-investigated area of adolescents' wellbeing. Adolescents' perceptions of wellbeing components are partially aligned with popular academic models, but also different to adults' perceptions. Therefore, a broader definition of wellbeing is warranted, tailored to the adolescents' prototypical wellbeing representation (specifically incorporating the components enjoyment/having fun, feeling safe, and being kind/helpful). Besides adolescents' three most listed pathways to wellbeing (positive family relationships, positive friendships, and physical activity/sport), researchers may include activities around nature, digital entertainment, pets, kindness, and positive people in their promotional models. It is imperative that practitioners and researchers consider adolescents' perceptions in designing assessment measures and wellbeing programs, especially accommodating perspectives exclusive to different socioeconomic groups.

\section{Acknowledgements}

The authors are extremely grateful to the participants and school staff who made this research possible. Thanks also goes to Dr Lucy Hone for her careful review and editing of the manuscript.

\author{
Authors \\ Gazal Bharara \\ Auckland University of Technology \\ Scott Duncan \\ Auckland University of Technology \\ Aaron Jarden \\ University of Melbourne \\ Erica Hinckson \\ Auckland University of Technology
}

\section{Publishing Timeline}

Received 9 April 2019

Accepted 22 September 2019

Published 26 September 2019 


\section{References}

Aked, J., Marks, N., Cordon, C., \& Thompson, S. (2008). Five ways to well-being: A report presented to the Foresight Project on communicating the evidence base for improving people's wellbeing. London, United Kingdom: Nef.

Anderson, D. L., \& Graham, A. P. (2016). Improving student wellbeing: Having a say at school. School Effectiveness and School Improvement, 27(3), 348-366. http://dx.doi.org/10.1080/09243453.2015.1084336

Andresen, S., Bradshaw, J., \& Kosher, H. (2019). Young children's perceptions of their lives and well-being. Child Indicators Research, 12(1), 1-7. http://dx.doi.org/10.1007/s12187-018-9551-6

Baker, L., Green, S., \& Falecki, D. (2017). Positive early childhood education: Expanding the reach of positive psychology into early childhood. European Journal of Applied Positive Psychology, 1, 1-12.

Ben-Arieh, A. (2005). Where are the children? Children's role in measuring and monitoring their well-being. Social Indicators Research, 74, 573-596. http://dx.doi.org/10.1007/s11205-004-4645-6

Ben-Arieh, A., Casas, F., Frønes, I., \& Korbin, J. E. (2014). Multifaceted concept of child well-being. In A. BenArieh, F. Casas, I. Frønes, \& J. E. Korbin (Eds.), Handbook of child well-being: Theories, methods and policies in global perspective (pp. 1-27). Dordrecht: Springer Netherlands. 978-90-481-9063-8. https://doi.org/10.1007/978-90-481-9063-8_134

Bharara, G., Duncan, S., \& Jarden, A. (2018a). Raw data from adolescents' listings of pathways to wellbeing. Mendeley Data. http://dx.doi.org/10.17632/vznw58xcv5.1

Bharara, G., Duncan, S., \& Jarden, A. (2018b). Raw data from the prototype analysis of adolescents' perceptions of wellbeing components. Mendeley Data. http://dx.doi.org/10.17632/np445hd45b.1

Blaskova, J. L., \& McLellan, R. (2017). Young people's perceptions of wellbeing: The importance of peer relationships in slovak schools. International Journal of School \& Educational Psychology, 6(4), 1-13. http://dx.doi.org/10.1080/21683603.2017.1342579

Bott, D., Escamilia, H., Kaufman, S. B., Kern, M. L., Krekel, C., Schlicht-Schmälzle, R., ... White, M. (2017). The state of positive education. Dubai, UAE: World Government Summit and IPEN.

Bourke, L., \& Geldens, P. M. (2007). Subjective wellbeing and its meaning for young people in a rural Australian center. Social Indicators Research, 82, 165-187. http://dx.doi.org/10.1007/s11205-006-9031-0

Camfield, L., Streuli, N., \& Woodhead, M. (2010). Children's well-being in developing countries: A conceptual and methodological review. European Journal of Development Research, 22, 398-416. http://dx.doi.org/10.1057/ejdr.2010.11

Canadian Institute for Health Information. (2009). Improving the health of Canadians: Exploring positive mental health. Ottawa, Ontario: Author. Retrieved from https://www.cihi.ca/en/improving_health_canadians_en.pdf

Casas, F. (2011). Subjective social indicators and child and adolescent well-being. Child Indicators Research, 4(4), 555-575. http://dx.doi.org/10.1007/s12187-010-9093-z

Chaplin, L. N. (2009). Please may I have a bike? Better yet, may I have a hug? An examination of children's and adolescents' happiness. Journal of Happiness Studies, 10, 541-562. http://dx.doi.org/10.1007/s10902008-9108-3

Cloninger, C. (2004). Feeling good: The science of well-being. New York, NY: Oxford University Press.

Cook, C. R., Kilgus, S. P., \& Burns, M. K. (2018). Advancing the science and practice of precision education to enhance student outcomes. Journal of School Psychology, 66, 410http://dx.doi.org/10.1016/j.jsp.2017.11.004

Crivello, G., Camfield, L., \& Woodhead, M. (2009). How can children tell us about their wellbeing? Exploring the potential of participatory research approaches within young lives. Social Indicators Research, 90(1), 51-172. http://dx.doi.org/10.1007/s11205-008-9312-x

De Leeuw, R. H., \& Buijzen, M. (2016). Introducing positive media psychology to the field of children, adolescents, and media. Journal of Children and Media, 10(1), 39-46. http://dx.doi.org/10.1080/17482798.2015.1121892 
Diener, E., Scollon, C., \& Lucas, R. (2003). The evolving concept of subjective well-being: The multifaceted nature of happiness. Advances in Cell Aging and Gerontology, 15, 187-219. http://dx.doi.org/10.1016/S1566-3124(03)15007-9

Diener, E., \& Seligman, M. (2004). Beyond money: Toward an economy of well-being. Psychological Science in the Public Interest, 5(1), 1-31. http://dx.doi.org/10.1111/j.0963-7214.2004.00501001.x

Diener, E., Wirtz, D., Tov, W., Kim-Prieto, C., Choi, D. W., Oishi, S., \& Biswas-Diener, R. (2010). New wellbeing measures: Short scales to assess flourishing and positive and negative feelings. Social Indicators Research, 97(2), 143-156. http://dx.doi.org/10.1007/978-90-481-2354-4

Durie, M. (1985). A Maori perspective of health. Social Science \& Medicine, 20, 483-486. http://dx.doi.org/10.1016/0277-9536(85)90363-6

Education Review Office. (2013). Wellbeing for success: Draft evaluation indicators for student wellbeing. Wellington, New Zealand: Author.

Education Review Office. (2015a). Wellbeing for success: A resource for schools. Wellington, New Zealand: Education Review Office. Retrieved from http://www.ero.govt.nz/publications/wellbeing-for-successa-resource-for-schools/

Education Review Office. (2015b). Wellbeing for young people's success at secondary school. Wellington, New Zealand: Author. Retrieved from http://www.ero.govt.nz/assets/Uploads/ERO-WellbeingSecondSchools-web.pdf

Education Services Australia. (n.d.). Australian student wellbeing framework. Carlton South, VIC, Australia: Education Council. Retrieved from https://studentwellbeinghub.edu.au/media/9310/aswf_booklet.pdf

Fattore, T., Mason, J., \& Watson, E. (2007). Children's conceptualisation(s) of their well-being. Social Indicators Research, 80(1), 5-29. http://dx.doi.org/10.1007/s11205-006-9019-9

Fattore, T., Mason, J., \& Watson, E. (2009). When children are asked about their well-being: Towards a framework for guiding policy. Child Indicators Research, 2, 57-77. http://dx.doi.org/10.1007/s12187-0089025-3

Fehr, B. (1988). Prototype analysis of the concepts of love and commitment. Journal of Personality and Social Psychology, 55, 557-579. http://dx.doi.org/10.1037/0022-3514.55.4.557

Fehr, B., \& Russell, J. A. (1984). Concept of emotion viewed from a prototype perspective. Journal of Experimental Psychology, 113, 464-486. http://dx.doi.org/10.1037/0096-3445.113.3.464

Gilman, R., \& Huebner, S. (2003). A review of life satisfaction research with children and adolescents. School Psychology Quarterly Summer, 18, 192-205. http://dx.doi.org/10.1521/scpq.18.2.192.21858

Hone, L. C., Jarden, A., Schofield, G., \& Duncan, S. (2014). Measuring flourishing: The impact of operational definitions on the prevalence of high levels of wellbeing. International Journal of Wellbeing, 4(1), 62-90. http://dx.doi.org/10.5502/ijw.v4i1.4

Hone, L. C., Schofield, G., \& Jarden, A. (2015). Conceptualizations of wellbeing: Insights from a prototype analysis on New Zealand workers. New Zealand Journal of Human Resource Management, 15(2), 97-118. Retrieved from http://www.nzjhrm.org.nz/

Horner, R., Blitz, C., \& Ross, S. W. (2014). The importance of contextual fit when implementing evidence-based interventions. Washington, DC: Office of the Assistant Secretary for Planning and Evaluation, Office of Human Services Policy, U.S. Department of Health and Human Services.

Huppert, F. A., \& So, T. T. (2013). Flourishing across europe: Application of a new conceptual framework for defining well-being. Social Indicators Research, 110, 837-861. http://dx.doi.org/10.1007/s11205-011-99667

Jarden, R. J., Sandham, M., Siegert, R. J., \& Koziol-McLain, J. (2018). Intensive care nurse conceptions of wellbeing: A prototype analysis. Nursing in Critical Care, 23, 324-331. http://dx.doi.org/10.1111/nicc.12379

Kearns, J. N., \& Fincham, F. D. (2004). A prototype analysis of forgiveness. Personality and Social Psychology Bulletin, 30(7), 838-855. http://dx.doi.org/10.1177/0146167204264237 
Keyes, C. L. (2005). Mental illness and/or mental health? Investigating axioms of the complete state model of health. Journal of Consulting and Clinical Psychology, 73(3), 539-548. http://dx.doi.org/10.1037/0022006X.73.3.539

Keyes, C. L. (2013). Mental well-being. New York, NY: Springer.

Lambert, N. M., Graham, S. M., \& Fincham, F. D. (2009). A prototype analysis of gratitude: Varieties of gratitude experiences. Personality and Social Psychology Bulletin, 35, 1193-1207. http://dx.doi.org/10.1177/0146167209338071

Land, K. C., Lamb, V. L., \& Mustillo, S. K. (2001). Child and youth well-being in the United States, 1975-1998: Some findings from a new index. Social Indicators Research, 56(3), 241-318. http://dx.doi.org/10.1023/a:1012485315266

Layous, K., Nelson, S. K., Oberle, E., Schonert-Reichl, K. A., \& Lyubomirsky, S. (2012). Kindness counts: Prompting prosocial behavior in preadolescents boosts peer acceptance and well-being. PLoS One, 7(12), e51380. http://dx.doi.org/10.1371/journal.pone.0051380

Marchant, M., Heath, M. A., \& Miramontes, N. Y. (2012). Merging empiricism and humanism: Role of social validity in the school-wide positive behavior support model. Journal of Positive Behavior Interventions, 15(4), 221-230. http://dx.doi.org/10.1177/1098300712459356

Mental Health Foundation of New Zealand. (2018). Mental health-wellbeing. Retrieved 13 February 2018, from https://www.mentalhealth.org.nz/home/ways-to-wellbeing/.

Ministry of Education. (2018). School deciles. Retrieved 15 February, 2018, from https://www.education.govt.nz/school/running-a-school/resourcing/operational-funding/schooldecile-ratings/

Ministry of Youth Development. (2004). Youth development: Strategy Aotearoa. Wellington, New Zealand: Author.

Norrish, J. M. (2015). Positive education: The Geelong Grammar School journey. New York, NY: Oxford University Press.

Norrish, J. M., Williams, P., O'Connor, M., \& Robinson. (2013). An applied framework for positive education. International Journal of Wellbeing, 3, 147-161. http://dx.doi.org/10.5502/ijw.v3i2.2

Purewal, R., Christley, R., Kordas, K., Joinson, C., Meints, K., Gee, N., \& Westgarth, C. (2017). Companion animals and child/adolescent development: A systematic review of the evidence. International Journal of Environmental Research and Public Health, 14(3), 1-25. http://dx.doi.org/10.3390/ijerph14030234

Rees, G., \& Dinisman, T. (2015). Comparing children's experiences and evaluations of their lives in 11 different countries. Child Indicators Research, 8(1), 5-31. http://dx.doi.org/10.1007/s12187-014-9291-1

Renshaw, T. L., Furlong, M. J., Dowdy, E., Rebelez, J., Smith, D. C., O'Malley, M. D., . . Strøm, I. F. (2014). Covitality: A synergistic conception of adolescents' mental health. In M. J. Furlong, R. Gilman, \& S. H. E (Eds.), Handbook of positive psychology in schools (2nd ed., pp. 12-32). New York, NY: Routledge/Taylor \& Francis.

Rosch, E. (1975). Cognitive representations of semantic categories. Journal of experimental psychology, 104, 192233. http://dx.doi.org/10.1037/0096-3445.104.3.192

Ryff, C. D. (1989). Happiness is everything, or is it? Explorations on the meaning of psychological well-being. Journal of Personality and Social Psychology, 57, 1069-1081. http://dx.doi.org/10.1037/0022-3514.57.6.1069

Ryff, C. D., \& Keyes, C. L. (1995). The structure of psychological well-being revisited. Journal of Personality and Social Psychology, 69, 719-727.

Sarriera, J. C., \& Bedin, L. M. (2017). Psychosocial well-being of children and adolescents in Latin America: Evidencebased interventions (Vol. 16). Cham, Switzerland: Springer International. http://dx.doi.org/10.1007/9783-319-55601-7

Seligman, M. E. (2011). Flourish: A visionary new understanding of happiness and well-being. New York, NY: Free Press. 
Seligman, M. E., Ernst, R., Gillham, J., Reivich, K., \& Linkins, M. (2009). Positive education: Positive psychology and classroom interventions. Oxford Review of Education, 35, 293-311. http://dx.doi.org/10.1080/03054980902934563

Soutter, A. K., O'Steen, B., \& Gilmore, A. (2012). Students' and teachers' perspectives on wellbeing in a senior secondary environment. Journal of Student Wellbeing, 5(2), 34-67. Retrieved from https://www.ojs.unisa.edu.au/index.php/JSW/article/download/738/582

Suldo, S. M., \& Savage, J. A. (2016). The Well-Being Promotion Program: A selective intervention for adolescents. In Promoting student happiness : Positive psychology interventions in schools (pp. 64-86). New York, NY: The Guilford Press.

UNESCO. (2004). Changing teaching practices: Using curriculum differentiation to respond to students' diversity. Paris, France: United Nations Educational, Scientific, and Cultural Organization. Retrieved from unesdoc.unesco.org/images/0013/001365/136583e.pdf

United Nations General Assembly. (1989). Convention on the rights of the child. New York, NY: Author.

Weiser, D. A., Lalasz, C. B., Weigel, D. J., \& Evans, W. P. (2014). A prototype analysis of infidelity. Personal Relationships, 21, 655-675. http://dx.doi.org/10.1111/pere.12056

Westerhof, G., \& Keyes, C. (2010). Mental illness and mental health: The two continua model across the lifespan. Journal of Adult Development, 17(2), 110-119. http://dx.doi.org/10.1007/s10804-009-9082-y 